\title{
DESENVOLVIMENTO DE UM MONITOR MULTIPARAMÉTRICO PARA AFERIÇÃO DE SINAIS BIOLÓGICOS
}

\author{
EB Gouveia*, MMO Silva*, RGQ Silva*, RSL Filho* \\ * Universidade Federal de Uberlândia, Uberlândia, Brasil \\ e-mail: ronaldo_dim@hotmail.com
}

Resumo: O objetivo desse trabalho é o desenvolvimento de um monitor multiparamétrico capaz de captar e exibir os sinais de respiração, pulsação, temperatura e GSR (Resposta Galvânica da Pele) de um ser humano. Nosso projeto visou o desenvolvimento do método de captação desses sinais por meio de sensores e o desenvolvimento de uma interface de exibição dos dados ao usuário.
Palavras-chave: monitor multiparamétrico, engenharia biomédica, resposta galvânica da pele, pulsação, temperatura, respiração.

Abstract: The purpose of this work is the development of a multiparameter monitor capable of capturing and displaying the signs of breathing, pulse, temperature 
and GSR (galvanic skin response) of a human being. Our project aims to develop capture method these signals through sensors and the development of a display interface of the user data.

Keywords: multiparameter monitor, biomedical engineering, galvanic skin response, pulse, temperature, breathing.

\section{Introdução}

Um monitor multiparamétrico é um aparelho que apresenta vários parâmetros relacionados ao usuário que está conectado, como por exemplo, eletrocardiograma, pressão arterial, temperatura, respiração, oximetria, entre outros. Este aparelho é muito utilizado na medicina para monitoramento do paciente.

Com o avanço na área tecnológica esses aparelhos têm se desenvolvido, se tornando cada vez mais seguros e acessíveis, melhorando a qualidade do monitoramento em pacientes.
No nosso projeto propomos criar um monitor que irá medir os sinais de frequência respiratória, frequência cardíaca, temperatura corpórea e resposta galvânica da pele (GSR).

A respiração pode ser entendida como a inalação e a exalação de ar pelo corpo ou também como a troca gasosa, $\mathrm{CO} 2$ por $\mathrm{O} 2$, que ocorre nos alvéolos pulmonares [1]. Durante a respiração o abdome se movimenta sempre que inspiramos e expiramos. $\mathrm{Na}$ inspiração os músculos intercostais externos e o diafragma contraem, na expiração basta o relaxamento dos contraídos na inspiração, o movimento desses músculos é perceptível visualmente e possibilitam a mensuração da frequência respiratória. Em média um ser humano respira em repouso de 12 a 18 vezes por minuto, podendo variar quando está em repouso ou em momentos de atividade física [2].

A frequência cardíaca de um ser humano em repouso é em média $72 \mathrm{bpm}$ (batimentos por minutos), isto é, ocorrem cerca de 72 sístoles e diástoles por 
minutos no coração. A sístole é a contração ventricular, o que faz com que o sangue seja ejetado do coração e levado para a periferia do corpo por diferença de pressão enquanto a diástole é o relaxamento do ventrículo o que causa o enchimento do mesmo [3]. Esse processo é cíclico.

Um método de medir a frequência cardíaca é observar os capilares dos dedos, que se enchem de sangue durante a sístole enquanto na diástole o fluxo de sangue nos capilares diminui. Esse fenômeno nos permite mensurar quantas vezes ocorre a contração observando o enchimento e esvaziamento dos capilares nos dedos, o que nos indica a quantidade de batimentos por minuto, e consequentemente, a frequência cardíaca.

A temperatura humana é em média $36^{\circ} \mathrm{C}$ a $36,5^{\circ} \mathrm{C}$ e não varia facilmente devido ao sistema termorregulador do corpo. Existem variações da mesma devido, ao local em que é aferida, por exemplo na axila a faixa é $35,5^{\circ} \mathrm{C}$ a $37^{\circ} \mathrm{C}$ enquanto na boca é $36^{\circ} \mathrm{C}$ a $37,4^{\circ} \mathrm{C}$. Em momentos de refeição, prática de exercícios, gestação ou ovulação, a temperatura eleva [4]. Quando há distúrbios fisiológicos no corpo o sistema regulador é afetado, o que gera a febre, hipotermia ou hipertermia. A febre, por exemplo, é causada pelo próprio corpo que aumenta a temperatura corporal para agir na defesa do organismo em caso de processo inflamatório, rejeição de enxerto, infecção, lesão tecidual, processo patológico entre outros, um importante papel como indicador de alguma lesão no organismo [5].

Galvanic Skin Response (GSR) mede a variação da resposta elétrica da pele. O sinal captado pode ser usado para averiguar a ação do sistema nervoso autonômico que está relacionado, por exemplo, com a atividade das glândulas sudoríparas. Uma vez que o sistema nervoso autonômico começa a agir, acionado por algum estímulo físico ou emocional, ambos desencadeiam uma resposta simpática nas glândulas sudoríparas aumentando a secreção. Embora este aumento de suor seja geralmente muito pequeno, o mesmo contém água e eletrólitos que aumentam a 
condutividade eléctrica da pele, diminuindo assim a resistência eléctrica da mesma. Essas mudanças, por sua vez afetam o GSR [6].

O GSR é muito utilizado em sessões de terapia, pois a variação do mesmo está intimamente ligada ao estado emocional da pessoa. Pacientes apresentam variações na resposta elétrica da pele quando constrangidas ou expostas a situações de estresse [7] o que faz o GSR ser uma ferramenta com inúmeras utilidades.

\section{Materiais e métodos}

A Figura 1 mostra os sensores utilizados e desenvolvidos para a mensuração dos sinais propostos.

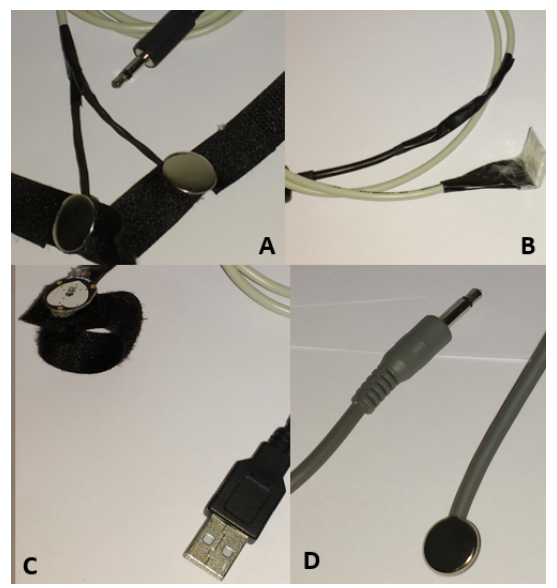

Figura 1: A figura mostra os sensores (a) GSR (b) frequência respiratória (c) frequência cardíaca (d) temperatura.

\section{Frequência Respiratória}

O acelerômetro é basicamente um dispositivo que mede a aceleração de um objeto em relação à gravidade. 
O funcionamento do acelerômetro é através de capacitores internos, sendo um deles móvel e outro fixo, quando a aceleração varia a distância entre esses capacitores também varia, consequentemente a capacitância. Sensores captam essa variação e respondem extraindo a aceleração. Utilizando 4 pinos do sensor, a alimentação, o terra (ground), o SDA (data signal) e o SCL (clock signal) através da comunicação $\mathrm{I}^{2} \mathrm{C}$ o sensor retorna valores em três eixos, $\mathrm{x}, \mathrm{y}$ e $\mathrm{z}$ da aceleração do objeto que está conectado. Pode ser configurado em escalas de $\pm 2 \mathrm{~g}, \pm 4 \mathrm{~g}$ ou $\pm 8 \mathrm{~g}$.

Para mensuração da frequência respiratória foi usado o acelerômetro que permitiu a captação do movimento do abdome. Esse movimento fornece dados ao sensor que nos permite plotar um gráfico do movimento captado o que gera um sinal, que após ser filtrado com um filtro digital de sexta ordem, forma uma onda senoidal.

Aplicamos a derivada no sinal obtido e observamos que, quando a inclinação da derivada alterar, temos um vale ou um pico, dessa maneira é possível contabilizar quantas vezes houve inspiração ou expiração, de modo que podemos mensurar a frequência respiratória.

\section{Frequência Cardíaca}

O sensor de pulsação usado tem sua tecnologia baseada em emissão e recebimento de luz infravermelha, de maneira que a variação lida pelo sensor tem estreita relação com a quantidade de luz que é refletida após entrar em contato com a superfície de interesse.

Coloca-se o sensor no dedo indicador, que por sua vez emite uma luz infravermelha que é refletida pelo dedo em intensidades diferentes dependendo da quantidade de sangue existente nos capilares do dedo no momento em que a luz é refletida. Por exemplo, se os capilares do dedo estiverem cheios de sangue, menos luz será refletida para o receptor, analogamente se os capilares 
do dedo estiverem com menos sangue mais luz será refletida para o receptor.

\section{Temperatura}

Utilizando o termistor NTC (Negative Temperature Coeficiente) em contato com o corpo o humano podemos medir a temperatura do mesmo de acordo com a variação da resistência do termistor. Utilizando a faixa de temperatura corporal humana $35^{\circ} \mathrm{C}$ a $40^{\circ} \mathrm{C}$ calculamos o coeficiente de variação da resistência do sensor com a temperatura utilizando medições práticas com ohmímetro e termômetro de mercúrio. Como referência usamos a tabela fornecida pelo fabricante, representada na Tabela 1, que possui todos os valores de resistência para as temperaturas correspondentes, assim através da tensão mensurada e com o coeficiente de variação calculamos a temperatura corporal e exibimos no monitor pela conexão com o Arduíno. Para o cálculo da temperatura foi utilizada a Equação 1, abaixo.

$$
{ }^{\circ} \mathrm{C}=-39,6 *\left(\left(\frac{1023}{\text { Leitura }}\right)-1\right)+62.02
$$

Tabela 1: Tabela do fabricante do sensor de temperatura

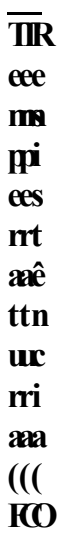




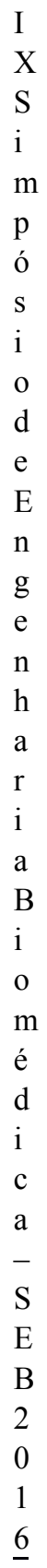

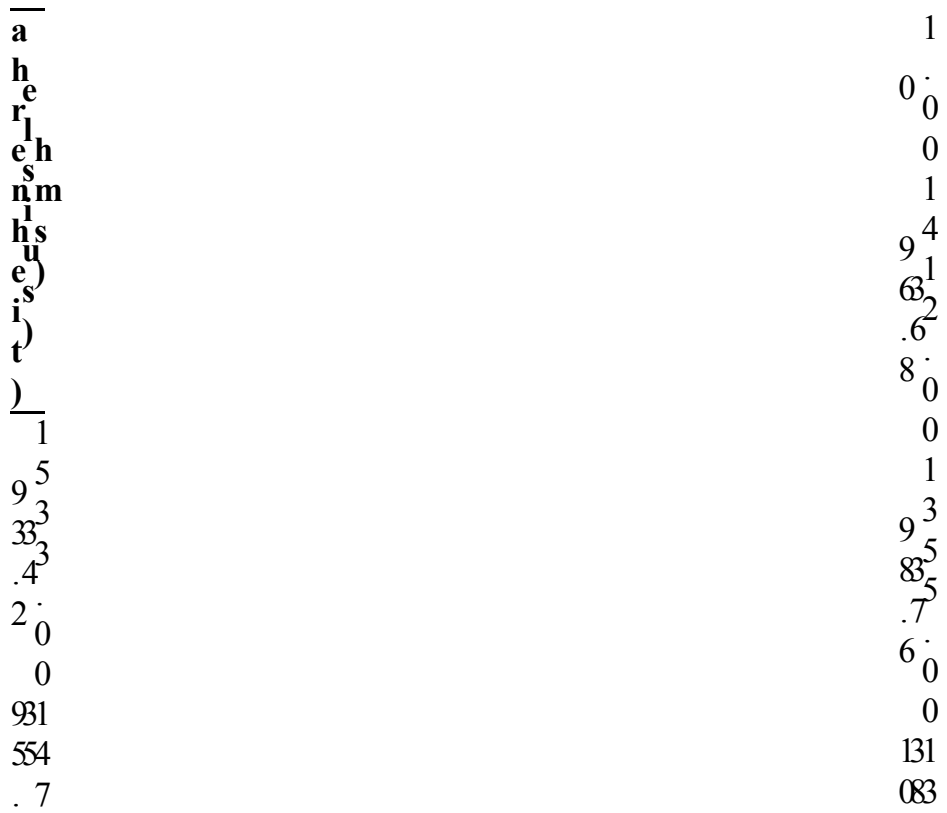




\section{Galvanic Skin Response}

O GSR é a resposta elétrica da pele que, por sua vez, é mensurada usando dois eletrodos posicionados nas falanges mediais do dedo indicador e médio. Esses locais foram escolhidos devido a quantidade de glândulas sudoríparas presentes na palma da mão, número que chega perto de 2000 [7].

Para mensurar a impedância da pele e assim verificar a resposta elétrica da mesma foi usado a ponte de Wheatstone [8] que nos permite manter um ponto de tensão fixo em uma extremidade da ponte enquanto a outra extremidade da ponte nos dá uma tensão variável, a qual tem sua variação de acordo com o divisor de tensão gerado por um potenciômetro e a impedância da pele. A tensão fixa e a tensão variável advinda da ponte de Wheatstone passam por um buffer e em seguida são ligadas à um amplificador subtrator que, por sua vez, amplifica a diferença de tensão entre os terminais do mesmo e nos dá um sinal que varia de acordo com a 
impedância da pele aferida pelos eletrodos, circuito que podemos observar na Figura 2.

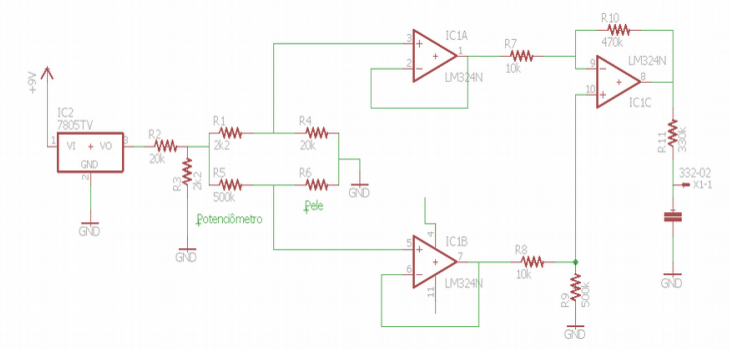

Figura 2: Circuito GSR

\section{Resultados}

O sistema desenvolvido mostrou-se uma ferramenta bastante válida tanto para fins acadêmicos quanto na obtenção de sinais biológicos.
A Figura 3 mostra o protótipo desenvolvido do monitor multiparamétrico, no qual a parte dianteira é composta pela conexão dos sensores e uma chave para ligar e desligar o equipamento. A parte superior do equipamento é composto pelo LCD no qual é exibido a temperatura corpórea e a frequência respiratória em batimentos por minuto.

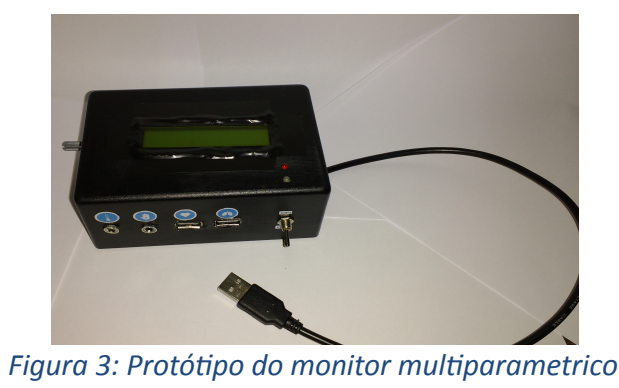


$\mathrm{O}$ acelerômetro se mostrou interessante na mensuração da frequência respiratória. Foram feitos vários testes comprovando a eficiência do mesmo, onde o usuário respirava de maneira aleatória e com o método de tratamento de dados desenvolvidos era possível perceber satisfatoriamente o padrão de respiração do usuário, um desses testes é representado na Figura 4.

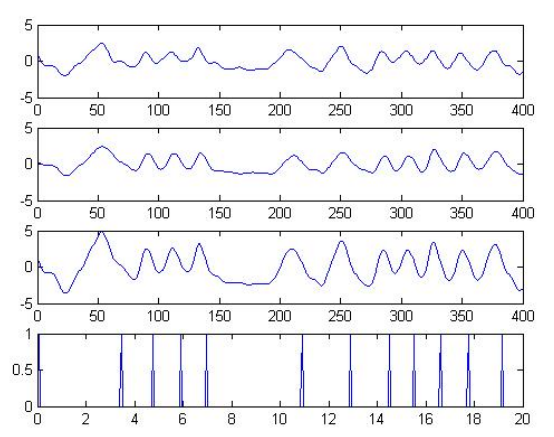

Figura 4: Teste acelerômetro e tratamento dos dados Gráficos nos eixos $x, y$ e $z$, respectivamente, e a análise pela derivada no ultimo gráfico, possibilitando a mensuração da frequência respiratória

Verificou-se que o sensor de pulsação foi eficaz na mensuração da frequência cardíaca do usuário. Em testes realizados obteve-se aumento dos batimentos cardíacos logo após atividade física exaustiva, o que era o esperado. O sinal do usuário em repouso pode ser observado na Figura 6.

O termistor utilizado como sensor de temperatura apresentou resultado muito satisfatório. Para tal conclusão foram feitos testes comparativos com termômetros digitais e de mercúrio e observou-se que a diferença da temperatura acusada pelo sensor, quando comparada com a temperatura mensurada pelos termômetros encontrados no mercado, é muito baixa, próxima de $0,5^{\circ}$ Celsius. A temperatura mensurada pelo termistor pode ser observada na Figura 6. 
A resposta galvânica da pele pode ser facilmente observada usando um osciloscópio. $\mathrm{Na}$ Figura 5 observa-se o teste com o auxílio do osciloscópio, as variações observadas são consequências de estímulos dolorosos.

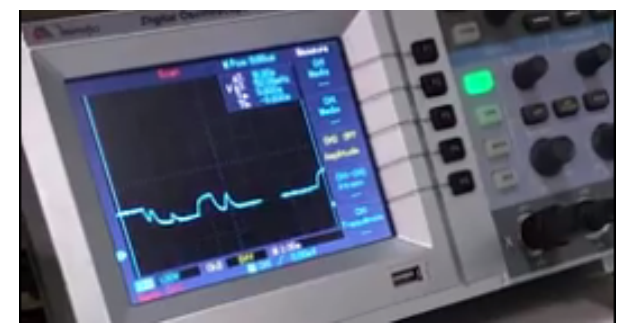

Figura 5: Resposta galvânica da pele mensurada em teste

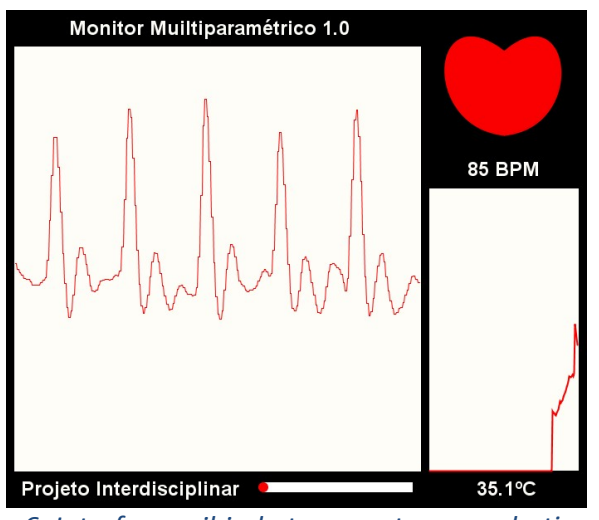

Figura 6: Interface exibindo temperatura e os batimentos cardíacos

\section{Discussão}

Durante os testes com o termistor percebemos que, quando o sensor permanece em atividade por um longo período de tempo, a temperatura começa a elevar de maneira incomum. $O$ aumento fantasma da 
temperatura é quase insignificante, $0.05^{\circ} \mathrm{C}$ por minuto, e se dá devido a corrente no termistor que contribui para a elevação da temperatura mensurada. Embora essa anomalia não seja ideal ela é presente nos equipamentos digitais encontrados no mercado que interrompem o processo de mensuração da temperatura quando a mesma se estabiliza, não permitindo assim que os mesmos permaneçam em atividade por longos períodos de tempo. Portanto tomamos a eficácia do sensor desenvolvido como aceitável.

Quanto ao uso do acelerômetro para mensuração da frequência respiratória percebemos que o sensor capta qualquer pequena variação de movimento o que dificultou a determinação da frequência respiratória do indivíduo. Para contornar esse problema foi necessário fazer o processamento dos dados advindos do sensor, para tanto utilizamos o software MATLAB e aplicamos um filtro passa alta no sinal para retirar as constantes da gravidade presente e retirar o nível DC imposto pela mesma, um filtro passa baixa de $2 \mathrm{~Hz}$ para retirar sinais indesejados de alta frequência presentes no movimento, aplicou-se também o Detrend para remover qualquer tendência linear do sinal recebido. Com isso o sinal se comportou de maneira senoidal em conformidade com o movimento do abdome do indivíduo, possibilitando a observação de picos e vales no movimento respiratório permitindo, assim, a determinação da frequência respiratória através da analisa da derivada do sinal processado.

A mensuração da frequência cardíaca por sensores infravermelho como usado é bem comum e tem um grau de segurança elevado.

A Resposta Galvânica da Pele se mostrou deficiente em alguns momentos devido a um nível DC que se somava ao sinal durante alguns testes. Acreditase que houve algum erro de projeto, porém pretende-se melhorar o mesmo para que essa anomalia não interfira na confiabilidade do sinal mensurado.

\section{Conclusão}


Por ser um equipamento muito utilizado na medicina por proporcionar segurança na sua aplicação e resultados eficazes, conseguimos desenvolver um monitor multiparamétrico aceitável, porém reconhecemos suas limitações momentâneas como, por exemplo, a mensuração da respiração ser limitada a uma só posição e o circuito do GSR não ser capaz de efetuar medidas em todos os testes de maneira eficaz.

Como trabalhos futuros, pretendemos prosseguir o estudo dos sensores utilizados no projeto, tal como no sensor de respiração, precisamos ampliar as possibilidades de medição, no qual possamos captar a respiração com o paciente em outras posições, além de deitado. No GSR precisamos melhorar o circuito para torná-lo ainda mais preciso na sua função e expandir o uso. Sobre a mensuração da temperatura pode-se ampliar a faixa de medição, o que não é útil para aferição em seres humanos, mas tem outras finalidades. A medição da frequência cardíaca foi satisfatória.

\section{Agradecimentos}

Os autores agradecem ao professor Adriano de Oliveira Andrade que foi o ministrante da disciplina que nos auxiliou a adquirir conhecimentos para a criação deste projeto. Aos alunos de doutorado Gustavo Moreira da Silva e Fábio Henrique M Oliveira que nos ajudaram a solucionar os problemas encontrado ao longo do projeto.

\section{Referências}

[1] Guyton, A.C.; Hall, J.E. Tratado de Fisiologia Médica. $11^{\mathrm{a}}$ ed. Rio de Janeiro, Elsevier Ed., 2006. p. 491.

[2] Guyton, A. C. Hall, J. E. - Tratado de Fisiologia Médica. $12^{\circ}$. ed. Rio de Janeiro: Elsevier, 2011.p.489.

[3] Guyton, A. C. Hall, J. E. - Tratado de Fisiologia Médica. $12^{\circ}$. ed. Rio de Janeiro: Elsevier, 2011.p.111-116. 
[4] Magalhães,S. et al. Termoregulação. Artigo e apoio, Porto, 2011 . Disponíve 1 e m : http://www.uff.br/WebQuest/downloads/Termorreg.p df.

[5] Voltarelli, Júlio C. Febre e inflamação. Medicina, Ribeirão Preto 27.1/2 (1994): 7-48.

[6] V S. Ramachandran, P.h.D e Sandra Blakeslee. Fantasmas no cérebro. In: Editora Record. São Paulo: 2014. p. 94.

[7] Westerink JHDM, van den Broek EL, Schut MH, van Herck J, Tuinenbreijer K. Computing emotion awareness through galvanic skin response and facial elemyography. Probing Experience, 149 - 162. 2008 Springer.

[8] Guedes MV. Método da ponte de Wheatstone. Núcleo de estudos em maquinas eletricas. 2003 [ citado em 20ll]. Disponivel em: paginas.fe.up.pt/TLME/LME_PontWhea.pdf 